\title{
Capacity for regeneration in crown of thorns starfish, Acanthaster planci
}

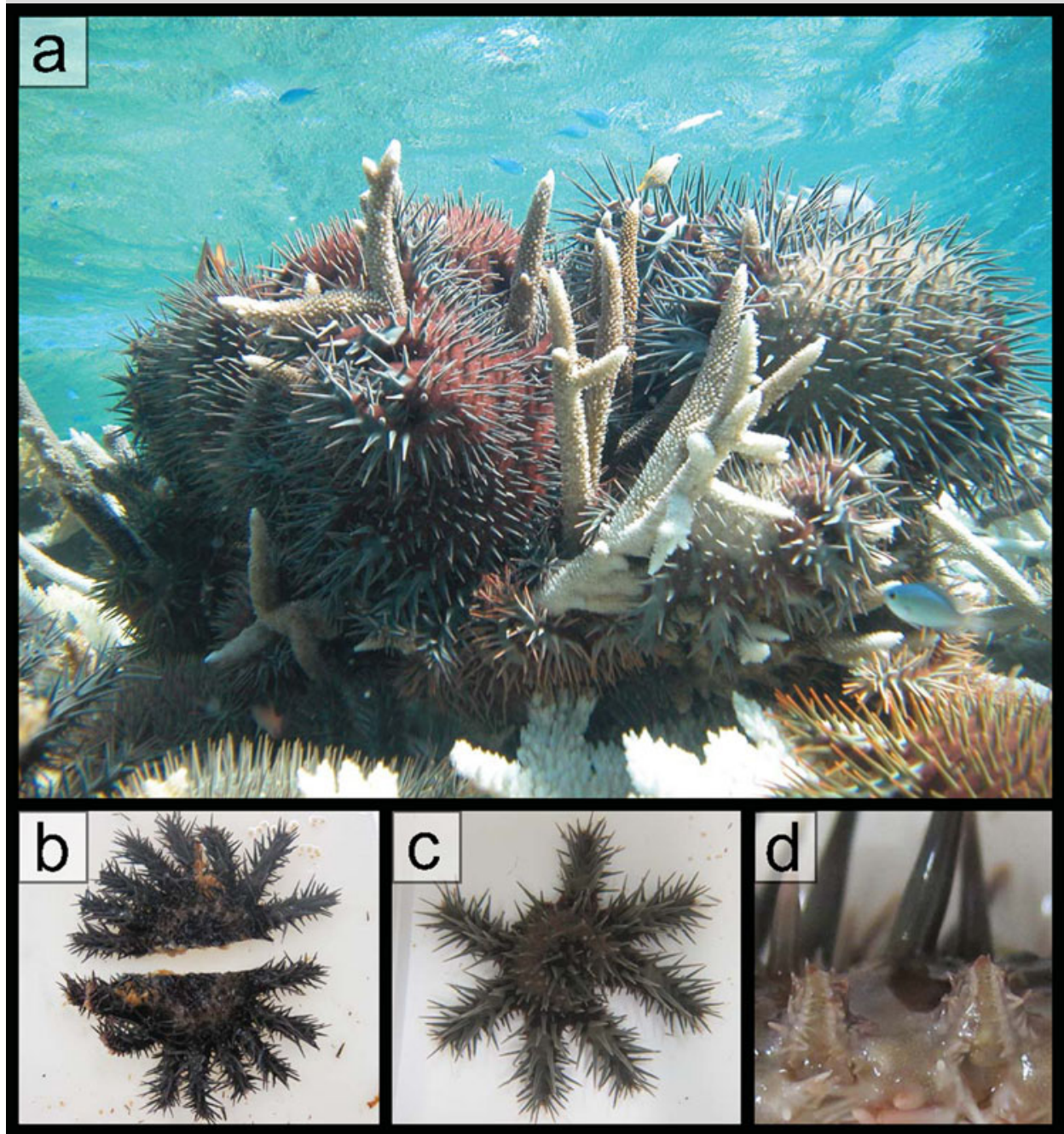

Fig. 1 a Acanthaster planci outbreak on the Great Barrier Reef; b A. planci cut into two equal halves; c after 7 weeks, both halves (only one pictured, one arm lost) were almost entirely healed; d A. planci starting to regenerate new arms after 6 weeks
Population outbreaks of the coral-feeding crown of thorns starfish, Acanthaster planci (Fig. 1a), are, with storms, the most significan disturbance on coral reefs in the western Pacific (e.g., De'ath et al. 2012). Controlling outbreaks of $A$. planci is therefore increasingly viewed as a key strategy in reducing coral loss and reef degradation. Initial control efforts in the 1960s involved sectioning starfish and leaving them in situ, but there were subsequent anecdotal reports that $A$. planci could regenerate from small pieces of remnant tissue. Regeneration is a common characteristic amongst echinoderms as a form of asexual reproduction, or following loss of appendages through predation, stress or disease. Regeneration has been recorded in at least 21 species within the Asteroidea (Emson and Wilkie 1980).

The capacity of $A$. planci to regenerate remains controversial. While $A$. planci is not known to undergo asexual reproduction, sectioned animals have been reported to survive for prolonged periods (Sweatman and Butler 1992). We cut four individuals into two equal halves (Fig. 1b), and another four individuals into two sections approximating $2 / 3$ and $1 / 3$. Animals were kept in individual flow-through tanks and photographed over a 7-week period. A total of $100 \%$ mortality was observed in all four $1 / 3$ segments within $3 \mathrm{~d}$. In contrast, $75 \%$ of both halves and $75 \%$ of $2 / 3$ segments survived. At 7 weeks, the wounds appeared to be greatly healed (Fig. 1c) and some of the segments were regenerating new arms (Fig. 1d). These results provide evidence that $A$. planci can regenerate from extensive tissue loss, but survivorship appears to be dependent on maintaining at least part of the central disc. Sectioning A. planci as a measure to control populations should be avoided in the absence of further knowledge regarding the survivorship, feeding ability and reproductive capacity of regenerated individuals.

Acknowledgments Funding was received through the Australian Museum's Lizard Island Research Station. Photo credit 1a Dr. Katharina Fabricius, Australian Institute of Marine Science.

\section{References}

De'ath G, Fabricius KE, Sweatman H, Puotinen M (2012) The 27-year decline of coral cover on the Great Barrier Reef and its causes. Proc Natl Acad Sci

USA on line doi:10.1073/pnas.1208909109

Emson RH, Wilkie IC (1980) Fission and autotomy in echinoderms. Oceanogr Mar Biol Annu Rev 18:155-250

Sweatman H, Butler I (1992) An experimental investigation of the ability of adult crown-of-thorns starfish to survive physical damage. Great Barrier Reef

Marine Park Authority, Workshop Series No 18:71-82

V. Messmer $(\bowtie) \cdot$ M. S. Pratchett

ARC Centre of Excellence for Coral Reef Studies, James Cook University, Townsville, QLD 4811, Australia

e-mail: vanessa.messmer@gmail.com

T. D. Clark

Australian Institute of Marine Science, Townsville, QLD 4810, Australia

Received: 2 December 2012/ Accepted: 6 February 2013/Published online: 20 February 2013

Coral Reefs (2013) 32:461

(C) Springer-Verlag Berlin Heidelberg 2013 